\title{
Ecological variation of intake of cassava food and dietary cyanide load in Nigerian communities
}

\author{
AO Onabolu ${ }^{1,2, *}$, OSA Oluwole ${ }^{1,2,3}, \mathrm{M} \mathrm{Bokanga}^{1}$ and H Rosling ${ }^{2}$ \\ 'International Institute of Tropical Agriculture (IITA), c/o LW Lambourn \& Co., 26 Dingwall Road, Croydon CR9 3EE, \\ UK: ${ }^{2}$ Division of International Health, Department of Public Health Sciences, Karolinska Institute, SE-171 76 \\ Stockholm, Sweden: ${ }^{3}$ Neurology Unit, Department of Medicine, University of Ibadan, Ibadan, Nigeria
}

Submitted 23 August 2000: Accepted 11 January 2001

\begin{abstract}
Aim: To study the ecological variation of intake of cassava foods and dietary cyanide load.

Design: Ecological study design.

Setting: Five communities in south-western Nigeria where tropical ataxic neuropathy (TAN) was described as endemic (area A), 11 communities in south-western Nigeria where TAN was described as absent (area B), and five communities in northern Nigeria (area C).

Subjects: Subjects were randomly sampled from selected communities. Intake of cassava foods was estimated from dietary history and dietary cyanide load was estimated from urine thiocyanate concentrations. Residual cyanogens in cassava food samples from the community markets were determined.

Results: In total, 1272 subjects from 21 communities - 238 from area A, 659 from area $\mathrm{B}$ and 375 from area $\mathrm{C}-$ were selected. Intake of cassava food per person per week was 17 meals in area A, 10 meals in area B, and one meal in area C. Geometrical mean urine thiocyanate concentrations were $73 \mu \mathrm{mol} \mathrm{l}^{-1}, 51 \mu \mathrm{mol} \mathrm{l}^{-1}$ and $17 \mu \mathrm{mol} \mathrm{l}^{-1}$ in areas A, B and C, respectively. Mean residual cyanogen content in

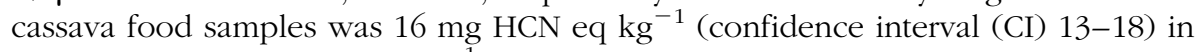
area A, and $13 \mathrm{mg} \mathrm{HCN} \mathrm{eq} \mathrm{kg}^{-1}$ in area B (CI 11-14).

Conclusion: This study shows that the intake of cassava foods and dietary cyanide load is high in several communities in south-western Nigeria, predominantly in communities where TAN has been reported. Dietary cyanide load in these communities appears to be determined by the combination of frequency of intake and cyanogen content of cassava foods. Measures to improve the effectiveness of removal of cyanogen from cassava roots during processing are needed in the affected communities.
\end{abstract}

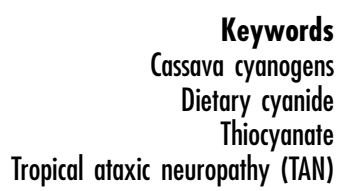

Cassava, a crop grown widely in the tropics $^{1}$, contains cyanogenic compounds ${ }^{2,3}$, which are reduced to residual amounts by processing ${ }^{4,5}$. Foods processed from cassava are sources of cyanide when residual cyanogens in such foods are consumed ${ }^{6,7}$. It is estimated that about 500 million people in the tropics and about 200 million people in Africa depend on cassava as a staple ${ }^{8}$. Several neurological syndromes seen in the tropics, like tropical ataxic neuropathy $^{9}$ (TAN), tropical amblyopia ${ }^{10}$ and $\mathrm{konzo}^{11}$, are attributed to cyanide released when cassava foods are eaten ${ }^{3}$. However, the intake of cassava foods almost exclusive of other foods in affected communities makes it difficult to entirely attribute causation to cyanide from cassava. In Nigeria, the intake of foods processed from cassava is reported to be high in several communities where TAN is prevalent ${ }^{12,13}$, but it is not known whether high dietary cyanide load is limited to these communities.

TAN, which was first reported from Nigeria in the mid$1950 s^{14,15}$, is a neurological syndrome of sensory polyneuropathy, gait ataxia, optic atrophy and neurosensory deafness ${ }^{13}$. Several communities in south-western Nigeria were reported to be endemic for TAN in the 1960s to early $1970 s^{9,13-15}$, but anecdotal reports ${ }^{13}$ suggested that the occurrence of TAN diminished in the 1980s following the economic boom of the 1970s in Nigeria. A recent study of one of these communities reported a higher prevalence of TAN in $1999^{16}$ than that reported for the community in $1969^{17}$. It is unclear if the increase in prevalence indicates a resurgence of TAN following the economic recession of the 1990s in Nigeria, and whether the current distribution 
of TAN remains confined to the communities previously described as endemic for TAN.

Nigeria, the world's largest producer of cassava in the past decade, currently produces about a third of Africa's annual cassava production ${ }^{18}$, but there is no information about the pattern of consumption at the level of communities. While some studies suggest that high cultivation of cassava is often accompanied by high consumption in several parts of Africa, a recent study of three Nigerian communities where production of cassava is high did not show a relationship between production and consumption of cassava foods ${ }^{19}$. The present ecological study was conducted to determine the intake of cassava foods and dietary cyanide load in a crosssection of Nigerian communities.

\section{Methods and subjects}

\section{Study area}

Three geographical areas within Nigeria were defined (Fig. 1) based on previous reports of being endemic for TAN $^{13-15}$ and consumption of cassava foods ${ }^{9,13,17}$. Area A included communities in south-western Nigeria where TAN was reported to be endemic and where consumption of cassava foods was high ${ }^{9,14,15}$; area B included communities in south-western Nigeria where TAN was reported to be absent and where consumption of cassava foods was $\operatorname{low}^{9,17}$; area $\mathrm{C}$ included some communities in northern Nigeria where TAN had not been described and where cassava is not the staple. The selected communities were situated along the axis of previous community studies for TAN in south-western Nigeria from Epe, a semi-urban community in the coastal area, to Oyo, a town further north. The distance between Epe and Oyo is about $150 \mathrm{~km}$. All of the intervening communities between Epe and Oyo that were within $2 \mathrm{~km}$ of the road between Epe and Oyo were identified. Five communities, inclusive of Epe, were selected from area A, and 11 communities from area B. Selection of communities, which started from Epe, was spaced to allow a distance of 5 to $10 \mathrm{~km}$ between the selected communities. Five communities were selected from area $\mathrm{C}$ to serve as reference.

\section{Subjects and dietary bistory}

In each community, subjects aged 8 to 9 years were randomly selected from the register of the major or only public primary school attended by the children of the community. There was no evidence of differential attendance of primary school with respect to socioeconomic status of the families in all but one of the communities, Ibadan. In Ibadan, one of the private primary schools attended by children from families with high socio-economic status was sampled in addition to three public primary schools. Young subjects were chosen for dietary interviews because local experience has shown that subjects of this age are less likely to give biased information of food intake compared with adults. History of all food taken in the family during the week preceding the interview was obtained from all subjects and recorded on a dietary history questionnaire, from where the number of cassava foods eaten during the week was counted.

\section{Collection, storage and analysis of cassava food}

The intake of gari, the most widely eaten cassava food in Nigerian communities, was used to estimate cyanogen intake. A recent study showed that gari is the major source of dietary cyanide among the common cassava foods in Nigeria ${ }^{7}$. Gari samples obtained from markets located in the communities in areas $\mathrm{A}$ and $\mathrm{B}$ were transported to the laboratory in polyethylene bags, and stored at $-20^{\circ} \mathrm{C}$ until analysis. Gari samples were not collected in area C where cassava is not the staple. Cyanogen content of the gari samples was analysed as previously described ${ }^{20}$.

\section{Collection, storage and analysis of urine samples}

Spot urine samples were collected between 08:00 and 09:00 $\mathrm{h}$ on the day of dietary interviews and transported on ice to the laboratory, where $5 \mathrm{ml}$ aliquots were stored at $-80^{\circ} \mathrm{C}$ until analysed for thiocyanate as previously described $^{21}$.

\section{Consent}

Consent for the study was obtained from the Local Government Health and Education Departments, the headteachers, parents and teachers' associations and community leaders.

\section{Statistics}

The confidence intervals (CIs) for mean intake of cassava food, mean cyanogen content of cassava food and geometrical means of urine thiocyanate in the three study areas were computed. The means of the intake of cassava food in the three study areas, and the mean cyanogen content of the cassava food, were compared with analysis of variance (ANOVA) and exact $P$ values are given. Multiple linear regression of geometrical mean urine thiocyanate of the communities in areas A and B on mean intake of cassava food in the communities and mean cyanogen content of the cassava food in the markets of the communities was done. All analyses were done with version 9 of SPSS statistical software.

\section{Results}

In total 1272 subjects were sampled: 238 in area A, 659 in area $\mathrm{B}$ and 375 in area $\mathrm{C}$. The distribution of intake of cassava food in each community is shown in Table 1. Intake of gari per person per week ranged from five to 21 meals in the communities in area $\mathrm{A}$, from zero to 21 meals 


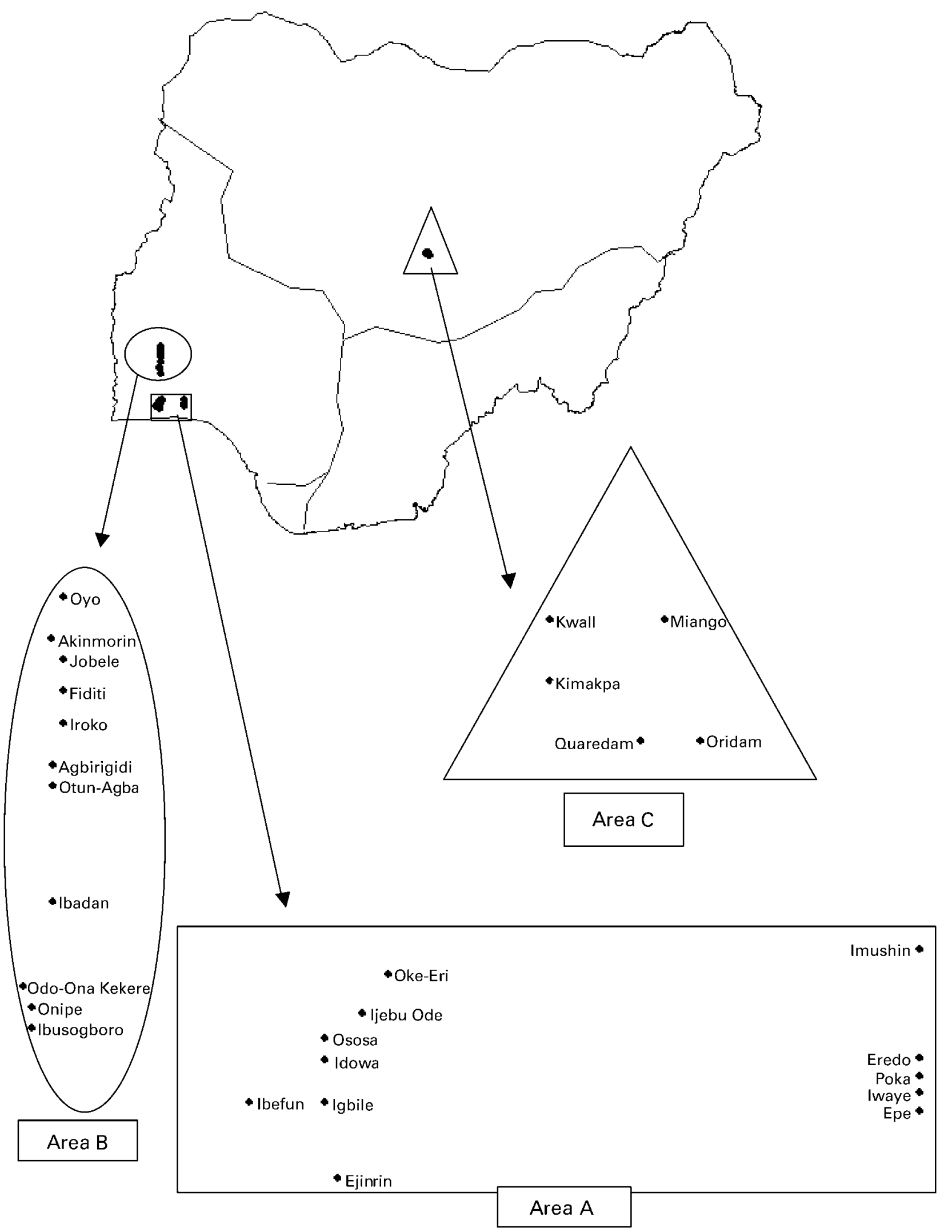

Fig. 1 Map of Nigeria showing the geographical areas defined in the study 
Table 1 Distribution of intake of cassava food and geometrical mean urine thiocyanate in communities

\begin{tabular}{|c|c|c|c|c|c|c|c|c|}
\hline \multirow[b]{2}{*}{ Community } & \multirow[b]{2}{*}{$n$} & \multicolumn{4}{|c|}{ Cassava meals per week } & \multirow{2}{*}{$\begin{array}{c}\text { Mean intake of } \\
\text { cassava/person/week }\end{array}$} & \multicolumn{2}{|c|}{ Urine thiocyanate $\left(\mu \mathrm{mol} \mathrm{I}{ }^{-1}\right)$} \\
\hline & & 0 & $1-7$ & $8-14$ & $15-21$ & & Range & Geometric mean \\
\hline \multicolumn{9}{|l|}{ Area $A^{*}$} \\
\hline Epe & 50 & 0 & 0 & 5 & 45 & 19 & $12-500$ & 83 \\
\hline Ososa & 53 & 0 & 2 & 12 & 39 & 16 & $10-214$ & 73 \\
\hline ljebu-Ode & 50 & 0 & 6 & 23 & 21 & 13 & $11-229$ & 62 \\
\hline Oke-Eri & 50 & 0 & 0 & 5 & 45 & 18 & $9-271$ & 72 \\
\hline Ajegunle-Awa & 35 & 0 & 0 & 4 & 31 & 18 & $14-376$ & 78 \\
\hline Total & 238 & 0 & 8 & 49 & 181 & 17 & $9-500$ & 73 \\
\hline \multicolumn{9}{|l|}{ Area $\mathrm{B} \dagger$} \\
\hline Onipe & 51 & 0 & 0 & 44 & 7 & 13 & $16-247$ & 47 \\
\hline Ibusogboro & 39 & 0 & 2 & 20 & 17 & 15 & $10-229$ & 50 \\
\hline Odona-Kekere & 50 & 0 & $\overline{6}$ & 32 & 12 & 12 & $12-416$ & 87 \\
\hline Ibadan & 189 & 1 & 74 & 86 & 28 & 10 & $5-259$ & 45 \\
\hline Otun-agba Akin & 50 & 0 & 7 & 37 & 6 & 11 & $2-241$ & 52 \\
\hline Agbirigidi & 33 & 0 & 7 & 23 & 3 & 10 & $14-140$ & 47 \\
\hline Iroko & 50 & 0 & 23 & 20 & 7 & 12 & $10-323$ & 42 \\
\hline Fiditi & 49 & 1 & 22 & 26 & 0 & 8 & $14-374$ & 52 \\
\hline Jobele & 49 & 1 & 13 & 20 & 15 & 13 & $22-2054$ & 103 \\
\hline Akinmorin & 50 & 1 & 49 & 0 & 0 & 6 & $13-108$ & 40 \\
\hline Oyo & 49 & 2 & 31 & 15 & 1 & 6 & $5-190$ & 37 \\
\hline Total & 659 & 6 & 234 & 323 & 96 & 10 & $2-2054$ & 51 \\
\hline \multicolumn{9}{|l|}{ Area C $\ddagger$} \\
\hline Miango & 122 & 60 & 62 & 29 & 0 & 1 & $0-275$ & 27 \\
\hline Qureedam & 71 & 51 & 20 & 0 & 0 & 1 & $0-443$ & 27 \\
\hline Oridam & 40 & 16 & 24 & 0 & 0 & 1 & $0-46$ & 8 \\
\hline Kimakpa & 70 & 53 & 17 & 0 & 0 & 0 & $1-330$ & 14 \\
\hline Kwall & 72 & 28 & 44 & 0 & 0 & 1 & $0-106$ & 10 \\
\hline Total & 375 & 208 & 167 & 0 & 0 & 1 & $0-443$ & 17 \\
\hline
\end{tabular}

* Area A includes south-western Nigerian communities where TAN has been described.

$\dagger$ Area B includes south-western Nigerian communities where TAN has not been described.

$\ddagger$ Area $\mathrm{C}$ includes northern Nigerian communities where TAN has not been described and where cassava is not the staple.

in the communities in area $\mathrm{B}$, and from zero to five meals in the communities in area $\mathrm{C}$. The mean intake per person per week was 17 meals in area A (CI 16-17), 10 meals in area B (CI 9-10), and one meal in area C (CI 0-1), $P<$ 0.0001. Post hoc comparison with Dunnett T3 showed significant differences in pairwise comparisons between the southern communities, and both the southern and northern communities.

The urine thiocyanate in the communities was in the range $9-500 \mu \mathrm{mol} \mathrm{l}^{-1}$ in area A, 2-2054 $\mathrm{mol} \mathrm{l}^{-1}$ in area $\mathrm{B}$, and $0-443 \mu \mathrm{mol} \mathrm{l}^{-1}$ in area $\mathrm{C}$ (Table 1 and Fig. 2). The geometrical mean urine thiocyanate was $73 \mu \mathrm{mol}^{-1}$ in area A (CI 66-80), $51 \mu \mathrm{mol} \mathrm{l^{-1 }}$ in area B (CI 48-54), and $17 \mu \mathrm{mol} \mathrm{l}^{-1}$ in area C (CI 15-19). Mean cyanogen content of cassava food samples from the markets was $16 \mathrm{mg}$ HCN eq kg ${ }^{-1}$ for area A (CI 13-18) and $13 \mathrm{mg} \mathrm{HCN} \mathrm{eq}$ $\mathrm{kg}^{-1}$ for area B (CI 11-14), $P=0.04$ (Table 2). Cyanogen content of $24(86 \%)$ cassava food samples from area A and $32(63 \%)$ of cassava food samples from area B exceeded the $10 \mathrm{mg} \mathrm{HCN} \mathrm{eq} \mathrm{kg}{ }^{-1}$ dry weight (dw) safety limit of the Food and Agricultural Organisation ${ }^{6,7}$.

Geometrical mean urine thiocyanate in the community correlated with mean intake of cassava food in the community $(r=0.7)$ and with mean cyanogen content of cassava food samples $(r=0.5)$. The regression model with mean intake of gari and mean cyanogen content of
Table 2 Mean cyanogen content of cassava food samples from community markets

\begin{tabular}{|c|c|c|}
\hline \multirow[b]{2}{*}{ Community } & \multicolumn{2}{|r|}{ Mean cyanogen content } \\
\hline & $n$ & 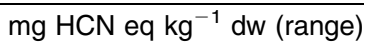 \\
\hline \multicolumn{3}{|l|}{ Area $A^{*}$} \\
\hline Epe & 7 & $11(5-17)$ \\
\hline Ososa & 5 & $17(10-24)$ \\
\hline ljebu-Ode & 8 & $17(11-30)$ \\
\hline Óke-Eri & 4 & $14(10-16)$ \\
\hline \multirow{2}{*}{ Ajegunle-Awa } & 4 & $20(12-32)$ \\
\hline & 28 & $16(5-32)$ \\
\hline \multicolumn{3}{|l|}{ Area B† } \\
\hline Ibusogboro & 4 & $14(7-18)$ \\
\hline Onipe & 2 & $11(9-13)$ \\
\hline Odo-Ona Kekere & 4 & $12(6-22)$ \\
\hline Ibadan & 12 & $10(4-21)$ \\
\hline Otun-agba Akin & 2 & $10(9-12)$ \\
\hline Agbirigidi & 4 & $11(9-13)$ \\
\hline Iroko & 3 & $8(7-9)$ \\
\hline Fiditi & 4 & $14(11-17)$ \\
\hline Jobele & 3 & $21(13-27)$ \\
\hline Akinmorin & 4 & $19(11-25)$ \\
\hline \multirow{2}{*}{ Oyo } & 9 & $13(7-18)$ \\
\hline & 51 & $13(4-27)$ \\
\hline
\end{tabular}

${ }^{*}$ Area A includes south-western Nigerian communities where TAN has been described.

† Area B includes south-western Nigerian communities where TAN has not been described. 


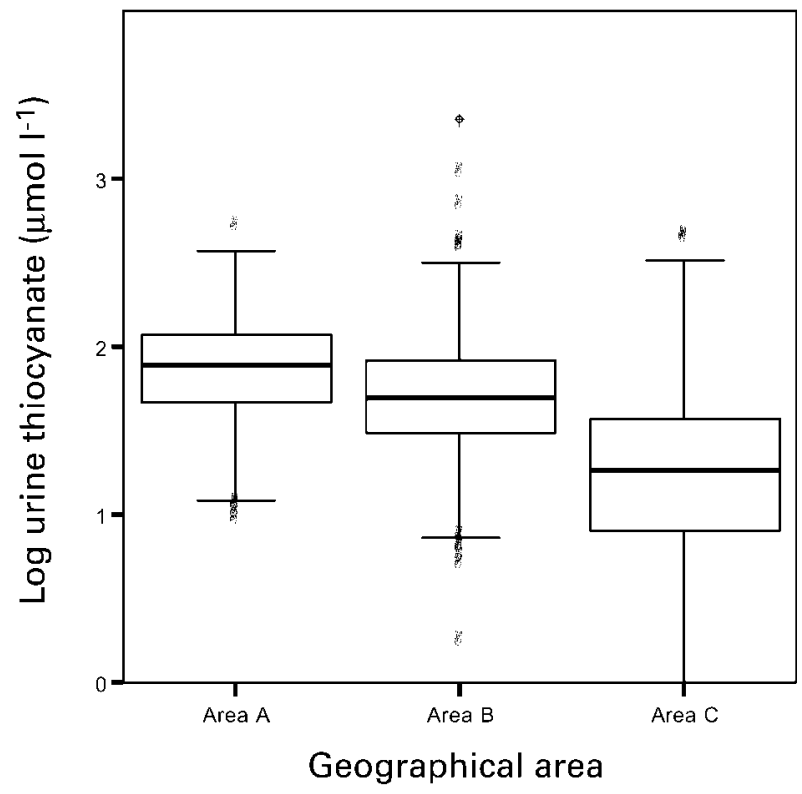

Fig. 2 Box plot of the distribution of log urine thiocyanate of the three geographical areas studied

gari samples as predictors of geometrical mean urine thiocyanate in the community explained about $60 \%$ of the variation of community urine thiocyanate $\left(R^{2}=0.6\right)$.

\section{Discussion}

This study shows that the intake of cassava food is high in the communities within the area previously designated as endemic for TAN in Nigeria compared with the intake of cassava foods in communities in south-western and northern Nigeria, where TAN has not been reported. The frequency of intake of cassava foods almost exclusive of other food types in these communities agrees with previous reports of monotonous consumption of cassava foods in the communities affected by $\mathrm{TAN}^{9,12}$. In these communities, high intake appears not to be determined by the intensity of cultivation of cassava, as these communities are not included in the areas of intense cultivation of cassava in Africa ${ }^{22}$. A recent study, which reported a low intake of cassava food in an area of high cultivation of cassava in Nigeria ${ }^{19}$, suggests that cultivation and consumption may not correlate in Nigerian communities. The pattern of food consumption in Nigerian communities is probably determined by the food culture of diverse communities populated by over 400 distinct ethnic groups.

The presence of high dietary cyanide load outside the geographical area where TAN has been described suggests that high dietary cyanide load is not exclusive to these communities. At the level of communities, two communities in south-western Nigeria have higher dietary cyanide load than the communities where TAN has been described, but at the level of individuals, high dietary cyanide load is present in all but one northern community. In south-western Nigeria, where cassava is the staple, the source of intake of cyanogens is easily attributable to cassava food, but in northern Nigeria where cassava is not staple, other dietary sources are probably responsible. It is noteworthy, however, that cassava foods are eaten in all of the communities in this study.

Although the frequency of intake of cassava foods has been used in most studies as the sole indicator of intake of cyanogens, this study suggests that both the frequency of intake of cassava foods and the cyanogen content of the cassava foods contribute to dietary cyanide load. The regression model shows that about $60 \%$ of the variation of urine thiocyanate concentrations in the communities is explained by the intake of cassava food and cyanogen content of gari samples from the community. This is shown in two communities, Jobele and Akinmorin, which have similar levels of cyanogen in their cassava foods, but only Jobele has high dietary cyanide load. High intake of cassava food in Jobele will explain this difference. Therefore, the frequency of intake of cassava food and the level of cyanogens in the foods are better predictors of dietary cyanide load in the community.

Several studies have shown that the level of residual cyanogens in foods processed from cassava is largely determined by the method of processing ${ }^{4,7,23}$. The method of processing, which varies in the communities where cassava is the staple, is determined by several factors like the availability of water to soak the roots, taste for the specific food products and shelf life of the food ${ }^{8}$. In the TAN-affected communities, the method of processing appears to be determined largely by the taste and other physical characteristics of the final gari product. The various methods of processing cassava in the communities where the mean cyanogen levels are high should be studied and improvement introduced as a public health measure to reduce dietary cyanide load.

The observation of high dietary cyanide load outside the geographical area where TAN has been described has implications for the hypothesised relationship of TAN to high intake of cassava cyanogens. TAN has not been described from Jobele and Odo-Ona Kekere, two communities outside the geographical areas were TAN has been described that have high dietary cyanide load. Epidemiological surveys of these communities for TAN are needed to show if high dietary cyanide at the level of the community is always accompanied by the presence of TAN.

In conclusion, this study shows ecological variation of the consumption of cassava foods in a cross-section of Nigerian communities. This variation is related to the frequency of intake of cassava foods and the cyanogen content of the foods. Improvement in the methods of processing cassava is needed to make cassava food safe for the millions of people who depend on it as a staple. The findings of this study will be a useful baseline for 
correlational ecological studies to establish the relationship between dietary cyanide and the occurrence of TAN in these Nigerian communities.

\section{Acknowledgements}

We acknowledge the support of the Local Government Education Authorities in charge of the various schools, the headmasters, pupils and parents to the conduct of the study. Funding for this study was provided by the International Sciences Programme of Uppsala University, Sweden.

\section{References}

1 Bellotti A, Smith L, Lapointe S. Recent advances in pest management. Annu. Rev. Entomol. 1999; 44: 343-70.

2 McMahon J, White W, Sayre R. Cyanogenesis in cassava (Manihot esculenta Crantz). J. Exp. Botany 1995; 46: 73141.

3 Spencer PS. Food toxins, AMPA receptors, and motor neuron diseases. Drug Metab. Rev. 1999; 31: 561-87.

4 Mlingi N, Abrahamsson M, Yuen J, Gebre-Medhin M, Rosling H. Low cyanide exposure from consumption of cassava in Dar es Salaam, Tanzania. Nat. Toxins 1998; 6: 67-72.

5 Banea-Mayambu J. High cassava consumption without cyanide exposure in Kinshasa, in former Zaire. Ecol. Food Nutr. 1998; 37: 363-73.

6 Rosling H. Measuring effects in humans of dietary cyanide exposure from cassava. Acta Horticult. 1994; 375: 271-83.

7 Onabolu A, Bokanga M, Rosling $\mathrm{H}$. Cassava processing in a Nigerian community affected by a neuropathy attributed to dietary cyanide exposure. Trop. Sci. 1999; 39: 129-35.

8 Bokanga M. Distribution of cyanogenic potential in cassava germplasm. Acta Horticult. 1994; 375: 117-23.

9 Osuntokun B. Epidemiology of tropical nutritional neuropathy in Nigerians. Trans. R. Soc. Trop. Med. Hyg. 1971; 65: 454-79.
10 Román GC, Spencer PS, Schoenberg BS. Tropical myeloneuropathies: the hidden endemias. Neurology 1985; 35: 1158-70.

11 Tylleskar T, Banea M, Bikangi N, Cooke RD, Poulter NH, Rosling H. Cassava cyanogens and konzo, an upper motoneuron disease found in Africa. Lancet 1992; 339 208-11.

12 Osuntokun BO. Cassava diet, chronic cyanide intoxication and neuropathy in the Nigerian Africans. World Rev. Nutr. Diet 1981; 36: 141-73.

13 Osuntokun B. Chronic cyanide intoxication of dietary origin and a degenerative neuropathy in Nigerians. Acta Horticult. 1994; 375: 311-21.

14 Money G. Endemic neuropathies in the Epe district of southern Nigeria. West Afr. Med.J. 1958; 7: 58-62.

15 Monekosso G. Clinical epidemiological observations on ataxic syndrome in Western Nigeria. Trop. Geog. Med. 1963; 4: 316-23.

16 Oluwole OSA, Onabolu AO, Link H, Rosling H. Persistence of tropical ataxic neuropathy in a Nigerian community. $J$. Neurol. Neurosurg. Psychiat. 2000; 69: 96-101.

17 Osuntokun B, Monekosso G, Wilson J. Relationship of a degenerative tropical neuropathy to diet report of a field survey. BMJ 1969; 1: 547-50.

18 Food and Agricultural Organisation. Cassava. Food Outlook 2000; 19-22.

19 Onabolu A, Tylleskar T, Bokanga M, Rosling H. High cassava production and low dietary cyanide exposure in Mid-West Nigeria. Public Health Nutr. 2001; 4(1): 3-9.

20 Essers A, Bosveld M, Van der Grift R, Voragen A. Studies on the quantification of specific cyanogens in cassava products and introduction of a new chromogen. J. Sci. Food Agric. 1993; 63: 287-96.

21 Lundquist P, Kagedal B, Nilsson L. An improved method for determination of thiocyanate in plasma and urine. Eur. $J$. Clin. Chem. Clin. Biochem. 1995; 33: 343-49.

22 Carter S, Jones P. A model of the distribution of cassava in Africa. Appl. Geog. 1993; 13: 353-71.

23 Chiwona-Karltun L, Tylleskär T, Mukumbira J, Gebre-Medhin M, Rosling H. Low dietary cyanogen exposure from frequent consumption of potentially toxic cassava in Malawi. Int. J. Food Sci. Nutr. 2000; 51: 33-43. 